\title{
English Discourse Markers in Mediatised Political Interviews
}

\begin{abstract}
The present case study takes a discourse-pragmatic approach to some of the most frequently used discourse markers (henceforth DMs) in spoken English: I mean, of course, oh, well, I think and you know. The point of departure in this research is a set of discourse-pragmatic relations and functions, such as conversation management, thematic control, concession, elaboration, reformulation, ventriloquizing, and marking evidentiality. After looking at which DMs signal these relations and functions in our corpora, we identify a set of English DMs whose members display markedly different pragmatic behaviours across various subgenres of spoken English such as naturally-occurring conversations and mediatised political interviews. We examine their use in a corpus of political interviews broadcast in English by the BBC and CNN between 2003 and 2011, and compare our results with previous research, performed on the basis of spontaneous, everyday conversations. Our paper has a threefold goal: (1) to present examples of the various discourse-organizing roles and strategic uses of the DMs; (2) to discuss the differences between the selected English DMs' functions across different subgenres of spoken English discourse; and (3) to answer whether or not the uses of the selected discourse markers differ across the various discourse types/genres (spoken English vs. different types of political interviews).
\end{abstract}

\section{Key words}

Discourse markers; pragmatic markers; media discourse; political discourse; genre analysis

\section{Introduction - the political interview as a genre}

A mediated political interview can be defined as a dyadic encounter between an interviewer (henceforth IR) and an interviewee (henceforth IE), directed at 
a public audience (Fetzer 2008). The nature of the political interview is best understood in terms of its formal-functional characteristics as institutional talk, (cf. Heritage and Greatbatch 1991) political discourse and mediated as well as mediatised discourse. The participants' roles, functions and underlying motivations are determined by the institutional setting in which political interviews are produced. As a result, the IR's role is to represent a media organization (in our corpora, the BBC and $\mathrm{CNN}$ ) in accordance with the specific guidelines set forth (such as guidelines for impartiality, accuracy, integrity, etc.), whereas the IE represents a political organization (political party, government, civil society, etc.) with a clear purpose to spread and propagate the organization's concepts, views, activities and slogans. Regarding the mediatisation of political interviews, it is commonly observed that in political interviews there are two different frames of interaction that occur simultaneously: a first-frame interaction between the IR(s) and the IE(s), as well as a second-frame interaction between the first-frame participants and the audience, either present in the studio or in front of their television sets (cf. Fetzer 2000). Thus, the political interview can be best described as a dialogue-within-dialogue scenario (cf. Fetzer 2008). Ideally, the IR voices the whole spectrum of public opinion, or at least, that of the target audience of the TV channel, while the IEs' aim is to gain favour with the audience, influence their views, beliefs, decisions, actions, etc. in a way that is beneficial to the organization represented.

From a structural-organizational perspective, political interviews can be described as dyadic with a very specific turn-taking mechanism and set of constraints: there is an asymmetrical relationship between the IR and the IE in that the former invariably produces the first-pair part of adjacency pairs ${ }^{1}$ (usually a question prefaced or followed by a comment), selects the IE as the next speaker, who produces the second-pair part (a response / reaction to the IR's preceding question or comment), and not vice versa. Due to the genre-specific norms of interviews as well as a set of expectations on the part of the audience, the content of the IE's turns always have to, at least, appear relevant to the IR's first-pair part. If, however, the IE's second-pair part is dispreferred (e.g. it expresses disagreement) or appears irrelevant, it is duly noted by the IR, a feature that is clearly different from the mechanisms of other genres such as naturally-occurring conversations. Moreover, the avoidance of direct/straight answers - usually introduced/marked by DMs, such as well - is also typical of political interviews. While political interviews are expected to proceed in a series of Q-A pairs, informal conversations are more likely to proceed in a less predictable manner and are intertwined with lengthy elaborations, narratives and side sequences as the speakers jump from one topic to another in a sometimes unmotivated way. Due to the different scenarios ${ }^{2}$ followed in these different discourse types, the functional spectra of DMs are also likely to differ in the discourse (sub)genres under scrutiny (political interview and political celebrity interview). For instance, most types of political interviews typically include face-threatening acts such as impolite, direct questions.

The above features of political interviews result in a set of pragmalinguistic realizations that are specific to this genre, the use of DMs being one of them. Before 
we discuss the genre-specific use of DMs in mediatised discourses, however, let us briefly sum up the features of this class of linguistic items.

\section{The study of discourse markers and their significance in genre analysis}

Discourse markers (DMs) ${ }^{3}$ are generally seen as a subclass of pragmatic markers (Fraser 1996, 2009) and can be defined as sequentially dependent elements which bracket units of talk (Schiffrin 1987), or metalinguistic items that provide information about the segmentation and operation of a discourse (Fraser 1999: 931). In other words, they signal the functional organization of discourse, the kinds of relations a speaker perceives between different parts of the discourse. Fraser (1999) suggests that that DMs link two sentences or clauses together. Redeker $(1991,2006)$ proposes that DMs connect not only adjacent clauses and sentences, but utterances and their contexts as well. Moreover, we argue that coherence relations expressed by DMs can even hold between utterances or topical units further apart from each other. Similarly, Lenk (1998) distinguishes between local DMs (marking utterance-level relations) and global DMs (marking topic relations). Global discourse markers (GDMs) may establish connections between different types of topic: they may refer back to a prior topic (retrospective GDM) or they might signal to the hearer that the speaker wants to insert something and they indicate what kind of contribution is likely to follow (prospective GDM). Following yet another terminology, Redeker (2006) talks about coherence-oriented marker uses, referred to as discourse operators, the definition of which is similar to discourse connectives in Relevance Theory (Blakemore 1992). Over the past few decades DMs have been researched from a variety of perspectives and theoretical frameworks such as Relevance Theory, Rhetorical Structure Theory, Construction Grammar, coherence-based studies, Interactional Sociolinguistics, Conversation Analysis, Speech Act Theory, Grammaticalization theories, Natural Semantic Metalanguage, Computational Pragmatics, etc. To highlight only one of the most significant of these approaches, Relevance Theory (Sperber and Wilson 1986/1995) draws attention to the role of DMs facilitating the hearer's task of decoding the message. In this view, DMs contribute to "relevance understanding by reducing the processing effort needed by the hearer to reach the intended interpretation" (Aijmer and Simon-Vandenbergen 2009: 16). In the framework of hearer-oriented models (focusing on interpretation), the role of markers is to provide instructions to the hearer on how to integrate the DMs' host utterances into a developing mental model of an optimally coherent discourse. From a cognitive perspective, DMs play an important role with regard to the processes of pragmatic inferences, in other words, in guiding hearers in their efforts to find out what is not explicitly stated but is implied by a given utterance. Because of DMs' potential to restrain the number of possible interpretations, a piece of discourse without discourse markers is often more ambiguous than intended. In Schiffrin's view of multilayered interaction, DMs create contextual coordinates that indicate for 
the hearer how an utterance is to be interpreted (1987). On the other hand, in the framework of speaker-oriented models of communication, DMs - which Östman calls pragmatic particles - implicitly convey the speaker's attitudes and emotions (Östman 1995). Similarly, in Schourup's view, these items are involved with a disclosure of covert thinking (1985). However, Schourup ignores discourseorganizational functions that we find equally salient uses of DMs.

Due to DMs' extreme multifunctionality and context-dependence, their study is especially relevant to genre-based analyses. Therefore, it is surprising that, in spite of the widespread interest in DMs in a variety of research fields including genre analysis, very few studies have investigated the role of DMs in mediatised political discourse. In the following section we will provide a brief overview of some of the most relevant case studies pertaining to English political interviews. After the description of our research corpus in section 4, we will try to narrow down the empirical gap in section 5 by describing some of the most frequent English DMs' genre-specific use in BBC news interviews and CNN political celebrity interviews.

\section{Previous studies}

\subsection{Previous research on mediatised political discourse}

Political interviews have been studied from several semantic, pragmatic and discourse-organizational perspectives, such as information structure, overlapping speech, discursive modes and manipulative language strategies, to mention but a few. However, as mentioned above, very few studies have focussed specifically on the role of DMs. A notable exception is Zovko (2012), who compared the use of DMs in interviews with presidents of Bosnia and Herzegovina with the functions of DMs in interviews with US presidents. There are a number of additional case studies, which, however, concentrate on particular DMs, such as of course or really, rather than the functional distribution of a set of DMs, cf. e.g. SimonVandenbergen (1988) or Simon-Vandenbergen et al. (2007).

\subsection{Previous accounts of the selected DMs in non-politicized discourse}

DMs have been predominantly studied in terms of their role in the organization of discourse structure in argumentative dialogues, sociolinguistic interviews (Schiffrin 1987), phone conversations, dialogues of highly interactive nature, and meeting conversations. Most studies focus on the analysis of a single DM, such as I mean or well. In what follows we will briefly sum up the perspectives leading DM researchers have taken to I mean and of course, the DMs whose genredependence is the most salient in our corpus.

Crystal and Davy (1975) demonstrate that I mean can be glossed as 'in other words', 'what I have been saying amounts to the following', or 'my specific mean- 
ing is that'. Its major role is to clarify the meaning of the speaker's immediately preceding stretch of speech or an expression that the speaker is reformulating. The inserted DM (I mean) is typically preceded by an interruption point, which disrupts the intonational contour of the utterance. Further functions include signalling a paraphrase or assessment of the previous utterance, performing an act of explanation/elaboration and/or providing a fresh angle about a previous topic as well as expressing a second thought/change of mind. Schiffrin defines I mean as a marker of the "speaker's upcoming modification of the meaning of his / her own prior talk." (Schiffrin 1987: 296) Its two main functions are "expansions of ideas" and "explanations of intention" (Schiffrin 1987: 296). Similarly, Swan argues that I mean introduces explanations, additional detail, opinion statements and corrections, while it can also serve as "a general-purpose connector of 'filler' with little real meaning" (Swan 1997: 159). Other functions include "softening" and "gaining time" (Swan 1997: 159).

Of course, similarly to I mean, has been described from a variety of perspectives: Holmes (1988) looks at the distribution of of course with respect to gender differences, Lewis (2006) takes a diachronic perspective and discusses rhetorical motivations for the development of a variety of its discourse-pragmatic functions. While Simon-Vandenbergen (1992) highlights the utility of of course in conversation management, Simon-Vandenbergen and Aijmer (2002/03) analyze of course from a cross-linguistic perspective as well as in the framework of Bakhtin's (1987) notion of heteroglossia ${ }^{4}$.

\section{The research corpora}

The corpus we compiled for the analysis of English DMs consists of 37 political interviews broadcast on BBC and 36 interviews broadcast on CNN. The individual interviews are between 30 minutes to 60 minutes long, thus, both the BBC and CNN corpora comprise a total of 79,225 words $\pm 2 \%$, allowing for technical / transcript-specific information such as the indication of participants' names. In our BBC corpus, IEs talk, on average, $71 \%$ of the time, while IRs' turns take up $29 \%$ of the interview time, in the CNN corpus, the ratio is $69 \%-31 \%$.

\section{Comparison of the use of DMs in mediatised interviews}

In the present section we discuss the results of a series of corpus-based analyses and provide the classification of DMs according to different contexts of use. The subsections describe the various textual relations and contextual factors DMs may mark in discourse. The relations and functions in question include elaboration/ expansion, reformulation/modification/ specification, lexical search, responsemarking vs. marking questions, evidentiality, ventriloquizing, and marking concession/alternative viewpoints. 


\subsection{DMs marking the IRs' and IEs' contrastive roles}

The IR's and the IE's respective roles in political interviews can be contrasted from the perspective of information management as well as conversational mechanisms. Political interviews are pre-planned events where the IR follows a predetermined set of questions and has a pre-allocated sequence of turns and topical units in mind, as opposed to natural conversation which is a type of spontaneous, unplanned discourse, without any specific scenario to be followed. Although political interviews may be viewed as pre-planned speech events, more of the planning characterizes the IRs' discourse which accounts for a smaller percentage of the overall discourse. As for information management, we can approach the function of I mean from the perspective of processing information along the lines of Jucker and Smith (1998), who distinguish between reception markers (e.g. $o h$, okay), which mark reactions to first-pair parts in adjacency pairs (e.g. statements, questions), and presentation markers, which elaborate on and/or alter the information provided by the previous speaker. Information-centred presentation markers, such as like modify the unit of information itself, while addressee-centred presentation markers, such as I mean relate the information to the assumed knowledge state of the addressee.

On the basis of tagging 143 tokens of the lexical item mean in our BBC corpus, the following patterns can be observed:

1. mean is a content word in 29 cases, but is a part of the DM I mean in the remaining 114 tokens;

2. I mean is primarily used by IEs (101 times), there are only 13 examples where an IR utters I mean, which is low, even considering the fact that IRs' talking time is longer than that of IEs (cf. section 4 above);

3. I mean functions as a filler in only 2 tokens, it marks false starts 17 times and cancels the content or the implicature of the previous utterance 9 times;

4. in the majority of cases (54 times in the case of IEs and 13 out of 13 times when uttered by an IR) I mean functions as a marker of explanation and/or elaboration.

Finding 1 above underscores the conversationalization of the genre under scrutiny: the high D-value ${ }^{5}$ of mean clearly indicates that present-day British political interviews bear the mark of conversational style. This tendency has been noticed by several researchers. Fetzer and Weizman (2006), for example, state that "politics has undergone dramatic changes [in that] the primarily monologue-oriented mode of discourse, which prevailed in the fifties, sixties, seventies and eighties, is no longer considered to be appropriate in the western and Anglo-American contexts" (Fetzer and Weizman 2006: 146).

Findings 2 and 3 are related to yet another aspect of the asymmetrical role between IRs and IEs: the higher incidence of I mean used by IEs can be explained, on the one hand, by the fact that the more comfortable one feels in a particular institutional setting, the less likely s/he needs to resort to discourse-monitoring uses 
of $\mathrm{DMs}^{6}$, such as stalling or lexical search. On the other hand, it is also related to the degree of planning that is involved on the part of IRs and IEs. Unplanned discourse is characterised by an increased number of discourse-monitoring DMs, this is why IEs are likely to use more tokens of I mean in general and more reformulative (rather than explanative) and opaque (i.e. semantically bleached) tokens of I mean in particular.

With regard to finding 4, two distinct structures can be observed as the most typical genre-specific uses of I mean: IRs most often use it in a [question preface + I mean + question] format (cf. example 1), while IEs tend to use it in an [answer preface / short answer + I mean + elaboration / example / explanation] structure (cf. example 2):

(1) IR: She's asked you about deaths of innocent people, I mean as a Christian how do you feel about innocent people dying? (BBC Newsnight, 6 February 2003)

(2) IR: You said this year, the concept of profit can and should play an increasing role in improving the quality of public services - how do you justify that?

IE: Well there are two things I'd say about that, I mean if you take the National Health Service for example 90 per cent of... (BBC Politics Show, 13 November 2005)

In what follows we will analyse various subtypes of elaboration and expansion, namely, modification, specification and explanation. In general terms, the elaboration of a previous aspect or aspects of the preceding discourse segment can take the form of clarification, specification or definition in terms of the notion or the idea conveyed in the previous discourse segment. We will, first of all, see if all these functions are expressed by I mean in English in our respective corpora.

González (2004) describes the functions of DMs, including I mean, with reference to story structure. Her research shows that the two most common functions of I mean in narratives are to mark (1) reformulation of previous information and (2) internal evaluation of the events presented in the narrative.

The less frequent occurrence of DMs associated with reformulation and lexical search in political discourse might also be considered strategic, since being understood exactly is less important than impressing the interlocutor/the audience as knowledgeable.

All in all, it is not surprising the discourse of the IR generally contains fewer instances of reformulation and lexical search than that of the IE. The confrontational character of these interviews, on the other hand, guarantees that the degree of planning on the IEs' part is only limited. However, similarly to the IRs, most IEs also prepare for the interview since their goal is to gain favour with the audience. 


\subsection{Of course - marker of evidentiality}

As described in section 1, there are two different layers of interaction present in political interviews: a first-frame interaction between the IR(s) and the IE(s) and the second-frame interaction between the first-frame participants and the audience. For the most part, there is a mismatch between the background information available to the IR and the (public) knowledge available to the audience whose voice the IR represents. The use of evidential markers makes this knowledge gap between the firstframe and second-frame participants explicit. The most common DM of evidentiality is of course in English, therefore, this DM will be described in the present section.

$\mathrm{O} f$ course has been variously classified as an expectation marker / marker of expectation (Simon-Vandenbergen and Aijmer 2002/03), expectation evidential (Chafe 1986), marker of speaker commitment (Lewis 2006) and marker of shared knowledge (Holmes 1988). Holmes (1988) proposes that of course acts "as an overt signal that the speaker is assuming that the hearer accepts or is already familiar with the propositional content of her or his utterance" (Holmes 1988: 53), while Wichmann et al. state that "of course has three broad levels of meaning: (1) epistemic / evidential - glossed as 'naturally', (2) interpersonal - glossed as 'shared knowledge', and (3) indeterminate" (Wichmann et al. 2010: 118).

Markers of evidentiality are typically more common in political interviews than in spontaneous conversations, moreover, there is only a partial overlap with the functions listed above: Simon-Vandenbergen et al. analyse British political news interviews, and find that the range of functions of course fulfils is markedly different from those that are observed in other discourse types and genres. They distinguish between three different functions of of course, the first can be glossed as 'as you know' (example 3), the second as 'it goes without saying' (example 4) and the third as 'as everyone knows' (example 5):

(3) Welcome to Petersfield in Hampshire which is decked out for Christmas and where we're in St. Peter's Church, which is renowned architecturally for its fine Norman tower and socially for its concerts, plays, exhibitions and civic events, as well as being of course a place of Christian worship. (SimonVandenbergen et al. 2007: 39)

(4) If there is to be a war on terror, and perhaps there must be, because of course September 11th was an outrage. (Simon-Vandenbergen et al. 2007: 40)

(5) We've had chief constables speaking publicly about the huge amount of resources that are going to be necessary to police a ban on foxhunting and $\boldsymbol{o f}$ course they've already tried to ban foxhunting in Scotland and the legislation is a complete nonsense... (Simon-Vandenbergen et al. 2007: 41)

The findings based on the BBC corpus used in the present study underscore Simon-Vandenbergen et al's conclusions: a mere 16 out of 85 tokens of of course 
are interactional, the remaining tokens are used in anticipation of an opposing viewpoint, and/or the IR's objections. However, instead of differentiating between 'as you know', 'it goes without saying' and 'as everyone knows', we found that it is more useful to categorize heteroglossic uses of of course into different degrees of anticipation and contrast: there are utterances where of course simply backgrounds the statement in its host unit, while in other cases it can be glossed as 'that's not the point' or 'that's totally irrelevant' as in examples 6,7 and 8 , respectively:

(6) IE: No I actually am more interested in not having a whole lot of time wasted for police and courts, as well as victims, with people uselessly maintaining their innocence. Some of them of course will get away with it 'cos they'll find a jury that believes what they say. I'm more interested if people are guilty that they show a bit of contrition, stop making things worse and admit straight away. (BBC5 Live, 18 May 2011)

(7) IE: Undoubtedly it does. Look, T. B. is right to say, as he did recently, that what happens in the Gaza Strip should not be an excuse for anyone to be radicalised. And of course that's right, but we have to deal with the world as it is.

(8) IR: Do you ... If you were in No. 10 at the moment and Nissan came to you, the other carmakers came to you and said, "We've done a very, very good job for this country. We've created a lot of employment. We need some help in the short-term", what would you tell them?

IE: Of course I want to help. But let's take Nissan because what... (BBC's The Andrew Marr Show, 11 January 2009)

In the $\mathrm{CNN}$ corpus, on the other hand, of course appears in contexts where its primary function is conversation management, for example, it serves as a response marker, feedback signal or topic change signal. In other contexts of course plays a role in information management: it marks lists / sequences, or shared background knowledge. Of course, similarly to I mean, occurs in narratives, where it can mark side sequences or new developments in the narrative. The interpersonal functions that were salient in the CNN corpus corresponded to and co-occurred with personal-centre switches, persuasion and solidarity, while in a few instances of course marked self correction, lexical search, or simply functioned as a filler (for a detailed analysis of the functional spectrum of of course in Larry King Live, cf. Furkó 2007).

The differences in the functional spectrum of of course in the two subcorpora can be traced back to the differences between the two types of political interviews. The confrontational quality of the BBC news interviews in the corpus is underlined by the fact that it is not only in terms of heteroglossia (i.e. anticipating objections and counterpoints) that of course is used differently in the two sub-genres, but in terms 
of its interactional uses, as well. While of course mostly marks strong agreement and/or feedback in the CNN Corpus, it is, for the most part, used to express token agreement in the $\mathrm{BBC}$ corpus, as is illustrated by examples 9 and 10, respectively:

(9) IR: Give it any thought, because that was a big rumor...

IE: Of course.

IR: Rumors always come around. (CNN Larry King Live, 17 March 2004)

(10) IR: The party was born from the unions wasn't it?

IE: ... of course, but we govern for the whole country. (BBC Politics Show, 12 September 2004)

\subsection{Markers of conversation management, information structure and thematic control}

Discourse markers are often used to regulate verbal interaction. It has been shown in a number of studies (cf. e.g. Petukhova and Bunt 2009) that discourse structure and coherence are maintained and expressed by various verbal markers. Coherence relations establish various links between discourse segments, and these relations are frequently expressed by DMs, such as well, you know, I mean or by the way. Besides marking boundaries, transitions and transition relevance places between discourse segments, DMs also signal the communicative function(s) of their host units. On the one hand, I mean and well may signal that the speaker has not finished his or her turn, but needs some time in the production process. On the other hand, hearers also use it to interrupt the current speaker's turn, signalling that the participant uttering the DM wishes to take the floor. Marked interactional behaviours such as taking the floor (grabbing a turn) by uttering a dispreferred second pair part or shifting the discourse topic have to be announced before they occur. Marked behaviours are labelled as dispreferred because the speakers are required to give an account of their acts in order to inform the listeners about the circumstances of / reasons for the unexpected response. Dispreferred answers such as disagreements are usually of 'No-plus' form (cf. Sacks 1992: 414) since they elaborate on the reasons for the negative reply (e.g. Actually, ...; Well). This pattern is illustrated by the following example:

(11) IR: You think the public expects her to...

IE: Well, not the public. The jury. (CNN Larry King Live, 27 February 2004)

The high incidence (401 tokens in an approximately 80,000 word corpus) and high D-value (82\%) of well, once again, underscores the conversationalization of political discourse. We find turn-initial well most frequently prefacing IEs' answers to IRs' (often overly direct) questions.

As the above examples from political interviews also suggest conversational turn openers can set up a frame for the entire turn, thus allowing interlocutors 
to predict what is going to come next in the conversation. In addition, turns that consist of a single DM can express a terse reaction to the previous turn. Heritage (2002), for instance, claims that turn-initial oh can indicate "epistemic independence', in other words, the suggestion that the idea following $o h$ was formulated by the speaker independently of the current conversation. Moreover, oh typically introduces an agreement rather than a disagreement with the previous turn. In contrast, as the examples demonstrate, well in turn-initial position usually signals disagreement.

Before we move on to the analysis of topic orientation markers, let us define the concept of discourse topic. Fraser (2009) provides a general definition of discourse topic as "what the discourse is currently about, what the participants recognize they are talking about from what has been contributed to this point". Chafe (1994) defines discourse topic in terms of the notion of semiactive information, and adds that the fact that speakers use DMs (e.g. you know, well or amugy 'by the way') before introducing a new topic suggests their awareness of a need to raise consciousness about their next move. In the following example well marks the speaker's intention to change the topic:

(12) IR: Back to the big question. Well, could there be a president with MS? (CNN Larry King Live, 6 March 2004)

Topic changes marked by DMs are more frequent in informal conversations than in our corpus of political interviews. The main reason for this is that while political interviews mostly centre on a focal topic, speakers in informal conversation tend to move from one topic to another and often completely change the topic of talk in an unmotivated way, which is usually made explicit by the use of DMs. On the other hand, the introduction of unsolicited opinion statements, additional information and side sequences is more common in political interviews than in informal conversation due to the high significance of expressing personal opinion, giving background information, listing arguments and opposing viewpoints in political interviews.

In the Larry King corpus, on the other hand, of course appears in contexts where its primary function is conversation management, for example, it serves as a response marker, feedback signal or topic change signal. In other contexts of course plays a role in information management: it marks, for example, lists / sequences, new information or shared background knowledge. Of course, similarly to I mean, occurs in narratives, where it can mark side sequences or new developments in the narrative. The interpersonal functions that were salient in the corpus based on Larry King Live corresponded to and co-occurred with personal-centre switches, persuasion and solidarity, while in a few instances of course marked self correction, lexical search, or simply functioned as a filler.

The differences in the functional spectrum of of course in Larry King Live and the other mediatized interviews in our corpus can be traced back to the differences between two types/subgenres of political interviews. TV broadcasts such 
as Larry King Live ${ }^{7}$ are of a less confrontational type, while several political interviews (especially Newsnight, Hard Talk and Question Time) take a more confrontational approach. From a discourse-pragmatic perspective, both sub-genres of political interviews are characterized by a repetitive sequence of adjacency pairs (Q-A-[comment]-Q-A-[comment], etc.) and a specific, asymmetrical roledistribution between IRs and IEs. However, as Lauerbach notes, in the case of Larry King Live the IR and the IE "collaboratively produce a consensual point of view" (Lauerbach 2007: 1388), while in more confrontational political interviews the IR "in asking the questions, takes into account what a sceptical audience would like to know" (Lauerbach 2007: 1394), exposing vagueness, evasiveness, and argumentative fallacies.

\subsection{Miscellaneous strategic uses: ventriloquizing and marking changes in cognitive states}

Voicing the discourse of others is a device by which speakers can distance themselves from what is being said, and position themselves in voices of others rather than their own (White 2000). As Goffman's (1981) states, a figure other than the speaker is being animated without the speaker being understood to be either the author of the words or to be responsible for them. If this is done by putting one's own words into the mouths of others, Goffman speaks of "say-foring" or ventriloquizing.

Tannen (2010) investigated the phenomenon of ventriloquizing as a device of indirectness in family interaction. She argues that ventriloquizing "creates meaning by abduction, as speakers borrow others' identities and thereby temporarily assign to themselves characteristics associated with those whose voices they borrow" (Tannen 2010: 307). She also argues that ventriloquizing can be understood as a type of indirectness, one that is very frequent in everyday interaction (Tannen 2010: 311).

Lauerbach (2006: 150) analyzed the practices of voicing and ventriloquizing and concluded that they have the effect of personalizing and dramatizing political discourse and implicitly construct identities and relations in the interplay between IR and IE. She describes ventriloquizing as "a particularly vivid way of enacting one's own discourse through another", which, in addition, "greatly increases the strategic potential of communicators" (Lauerbach 2006: 199).

Based on our corpus, the ventriloquizing use of $o h$ in political interviews is more salient than in the discourse genres ${ }^{8}$ that are traditionally studied in DM research. Examples 13 and 14 illustrate such uses:

(13) IE: Yes, to some extent. It's rather an odd situation we have here where the, the government are trying to legislate, or the House of Commons is trying to legislate very very quickly, that this is a bill that passed all its stages in the House of Commons, minimum of debate in one day, and then they say, $\boldsymbol{o h}$ it doesn't need to come in to effect for eighteen months or two years. (BBC Politics Show, 10 October 2004) 
(14) IE: When you talked about disenchantment with politics John, there's an awful lot of disenchantment with political coverage and Margaret talked about 'trial by ordeal', which is basically the media thinking, if we keep this story going long enough, eventually Tony Blair is going to say, $\boldsymbol{O} \boldsymbol{h}$ my god, I can't be doing with this, let's get rid of them. (BBC Politics Show, 12 March 2006)

In these examples $o h$ introduces statements and opinions that are attributed to people other than the IE (usually political opponents) in an effort to mock such opinions and/or make them sound ill-founded.

In yet another strategic use of oh, we can find it in the phrase Oh come on, which plays down the import of the previous speaker's (in this case the IR's) or an opponent's statement:

(15) IR: The polls... (overlaps)

IE: As I say, we're actually - $\boldsymbol{o h}$ come on Jeremy, you're talking about one poll that happens to have been taken recently. (BBC Politics Show, 11 July 2004)

In naturally-occurring conversations such uses of $o h$ are less salient, instead, $o h$ functions for the most part as a backchannel similarly to right, sure, aha; it can also express emphasis, glossed as 'certainly', or signal the receipt of information or acknowledgement similarly to really, I see, yes, and $O K$. In all such functions oh occurs turn-initially, therefore, the markedly higher I-value of $o h$ in naturally-occurring conversations (82\%) than in mediatized political interviews $(56 \%)$ comes as no surprise.

Naturally, there are a range of additional DMs that are used strategically in political interviews and whose description would deserve separate sections. Because of space considerations, however, in this section we will briefly illustrate the strategic use of well and you know in our corpus of political interviews, focussing on the patterns that have not emerged in studies based on other types of discourse.

Turn-internal uses of well show an interesting genre-specific pattern: we find a large number of utterances where well introduces ventriloquizing, once again, making the IEs' discourse more vivid and increasing its strategic potential (cf. Lauerbach 2006: 199 quoted above). However, unlike in the case of $o h$, the ventriloquizing uses of well introduce statements, positions or internal thoughts that are attributed to people (at times the speakers themselves) whose opinions are actually favourable to the IE (and the audience), thus there is no negative stance towards the ventriloquized utterance:

(16) IE: over the past 18 months, the eurozone governments have rather let us down, given us, you know, wonderful hope on the basis of the thrust of what they've been saying and then we've seen the fine print we've thought, "well, actually, there's rather less to all of this than we hoped." (BBC Radio 4 Today Programme, 6 September 2011) 
(17) IR: But what happens if an employer says, well all well and good, but we don't really want to see these union leaders, we've got better things to do. (BBC Politics Show, 12 September 2004)

Finally, as for the various strategic uses of you know, let us concentrate on two specific uses that, on the basis of our corpus, occurs as salient in confrontational types of political interviews. The first (example 18), once again, involves ventriloquizing:

(18) IE: I understand that and I know there's a lot of concern because people say well look, you know ... get rid of all the targets for waiting lists and our life would be easier. (BBC Newsnight, 7 February 2003)

The second salient function of you know is a strategic use subsequent to which speakers (usually IEs) let their voice trail off, without finishing a point they were making before, or without drawing a (usually embarrassing) conclusion:

(19) IE: it's not true to say that there's nothing getting better, and all I can talk about in terms of personal experience is my own constituency where I would say undoubtedly, you know... but if you look at the new North Durham Hospital, I mean that is a better hospital than what was there. (BBC Newsnight, 7 February 2003)

\subsection{Markers of concession, heteroglossia and alternative viewpoints}

Concession is a discourse-pragmatic relation signalling that the relationship between two ideas in two discourse segments is unexpected or surprising. This relationship is often marked with a DM such as of course in English.

We must also consider the influence of situational parameters that affect the frequency of the realization of concessive relations. It might seem logical that concession prevails in written modes of discourse due to the availability of a lot of time for planning and editing. In spite of this assumption, we can identify a large number of concessive relations in speech corpora, as well.

It is a common monologic argumentation strategy to introduce one's own concessions, thus, minimizing their salience and emphasizing one's own preferred course of argument, but we can observe it in dialogues, as well, especially in shorter narrative or argumentative parts of the IEs' speech in political interviews as well as in naturally-occurring conversation.

The relation of concession is frequently explicitly marked by DMs in political interviews partly due to Bakhtin's (1987) notion of heteroglossia. At the same time, concession can be regarded as a strategic means of anticipating potentionally forthcoming objections on the part of the IR, IE or the audience, thus showing oneself as knowledgeable and critical.

Simon-Vandenbergen et al. argue that the use of presupposition in general and its marking by of course in particular is a tactic employed by IEs in political inter- 
views, because "by using of course the speaker recognizes that the context is heteroglossic, $\mathrm{s} / \mathrm{he}$ is presented as responding to prior utterances, anticipating a response / alternative viewpoints" (Simon-Vandenbergen et al. 2007: 35ff). They reach the conclusion that (1) of course confirms solidarity with the like-minded, (2) construes solidarity with those who need to be persuaded; (3) conversely, of course can serve an oppositional function; and, finally, (4) of course contributes to the image of the speaker being 'in the know', its use gives the speaker "a temporary advantage in the battle for scoring with the audience" (Simon-Vandenbergen et al. 2007: 66).

The findings based on the corpus of political interviews used in the present study underscore Simon-Vandenbergen et al's conclusions: only 16 out of 85 tokens of of course are interactional, the remaining 69 tokens are used in anticipation of a contrasting viewpoint, and/or the IR's objections. We found it useful to categorize heteroglossic uses of of course into different degrees of anticipation and contrast: there are utterances where of course simply backgrounds the statement in its host unit, while in other cases it can be glossed as 'that's not the point' or 'that's totally irrelevant' as in examples 20, 21 and 21, respectively:

(20) IE: No I actually am more interested in not having a whole lot of time wasted for police and courts, as well as victims, with people uselessly maintaining their innocence. Some of them of course will get away with it 'cos they'll find a jury that believes what they say. I'm more interested if people are guilty that they show a bit of contrition, stop making things worse and admit straight away. (BBC5 Live, 18 May 2011)

(21) IE: Undoubtedly it does. Look, T. B. is right to say, as he did recently, that what happens in the Gaza Strip should not be an excuse for anyone to be radicalised. And of course that's right, but we have to deal with the world as it is. (BBC The Andrew Marr Show, 11 January 2009)

(22) IR: Do you... If you were in No. 10 at the moment and Nissan came to you, the other carmakers came to you and said, "We've done a very, very good job for this country. We've created a lot of employment. We need some help in the short-term", what would you tell them?

IE: Of course I want to help. But let's take Nissan because what... (BBC The Andrew Marr Show, 11 January 2009)

Rare uses of of course involve distancing the speaker from the proposition, expressing irony or disapproval; however, these functions are more frequent in naturally-occurring casual talk than in media discourse. In such contexts, the DM reinforces the implicature that the ideas are presented ironically.

We were particularly interested in comparing the frequency of reformulation and lexical search employed by the IR and IE respectively as we assume that IEs use more DMs associated performing these own speech management roles. Our 
hypothesis has been confirmed as IRs use less DMs with reformulation and lexical search roles than IRs. The less frequent occurrence of DMs associated with reformulation and lexical search in political interviews might be strategic (on part of the IR) since being understood is probably less important than impressing the interlocutor/the audience as savvy and well-informed.

Table 1 provides an overview of the functional correspondences that have been identified with reference to the DMs under scrutiny.

Table 1. Functional distribution of the most frequent DMs in our corpora

\begin{tabular}{|l|l|}
\hline Function & DM \\
\hline question preface, question marking & I mean \\
\hline reformulation & I mean, oh, well \\
\hline marker of expansion, explanation, elaboration & I mean, well \\
\hline lexical search, delay & I mean, well \\
\hline marker of evidentiality, marker of shared knowledge & of course, you know \\
\hline $\begin{array}{l}\text { management of information: marker of background } \\
\text { information and side sequences in narratives }\end{array}$ & of course, I mean, oh \\
\hline concession, alternative viewpoint & of course, well \\
\hline $\begin{array}{l}\text { attitude marker, response marker, reception marker, } \\
\text { commentary }\end{array}$ & $\begin{array}{l}\text { oh, well, of course, } \\
\text { I think }\end{array}$ \\
\hline topic change, topic shift & of course, well \\
\hline ventriloquizing & well, oh, you know \\
\hline
\end{tabular}

\section{Conclusions, directions for further research}

It can be concluded that our corpus displays recurrent coherence sequences. Some of these, such as question and answer sequences, are more often associated with interviews, while others, such as explanation, specification, approximation or example, are more likely to be associated with naturally-occurring talk. Therefore, genre seems to be a powerful variable in the production of discourse relations as well as the resulting patterns in the functional spectra of DMs.

We are fully aware that we have not even started to scratch the surface of what the cross-fertilization between genre analysis and DM research has to offer to both disciplines. What we hope to have illustrated is that DMs make an important contribution to the interpretation of various discourse segments, and that a primarily discourse-pragmatic, corpus-driven perspective on the functional spectra of individual DMs is a more fruitful approach than either semantic-taxonomic or systemic-functional methods, often adopted in the pertinent DM literature 9 . Naturally, further research is needed (cross-cultural as well as cross-linguistic, quantitative as well as qualitative) in order to substantiate our findings about, for example, DMs' contribution to heteroglossia, stance-taking and ventriloquizing, 
so that we can gain new and deeper insights about the functional spectrum of DMs as a heuristic tool for genre (or literary) analysis.

\section{Notes}

1 We use the terms adjacency pair, first- and second-pair part as in Schegloff (1972).

2 On the role of scenarios in interactions, cf. Csüry (2011).

3 Discourse markers have been called by a host of different names such as discourse connective, discourse operator, discourse particle, cue phrase, pragmatic marker, pragmatic force modifier, pragmatic expression depending on the approach taken to the linguistic items under discussion.

4 Bakhtin (1987) quoted in Simon-Vandenbergen and Aijmer (2002/03)

5 The categorial multifunctionality of DMs is described in terms of their "D-function ratio" or D-value (a term proposed by Stenström 1990), i.e. in terms of their discourse function in relation to their function as grammatical or content words. The D-value of $o h$, for example, is $100 \%$ in the London-Lund Corpus, since it is used exclusively as a DM, whereas well showed a D-value of $86 \%$.

6 Cf. e.g. O'Barr and Atkins's (1980) study of the use of DMs in courtroom settings.

7 According to Lauerbach, Larry King Live belongs to the "soft and feel-good genre" of "celebrity interviews" (Lauerbach 2007: 1388).

8 The ventriloquizing pattern of use of $o h$ in political interviews is different from typical discourse functions in other discourse genres e.g. naturally-occurring conversation (Stenström 1994), or sociolinguistic interviews (Schiffrin 1987).

9 For the primarily discourse-pragmatic, corpus-driven perspective, cf. e.g. Fraser (1996), as for the semantic-taxonomic or systemic-functional methods, cf. Halliday and Hasan (1976) and subsequent analyses.

\section{References}

Aijmer, Karin (1997) "I think - An English modal particle". In: Swan, Toril and Olaf J. Westvik (eds.) Modality in Germanic Languages. Historical and Comparative Perspectives. Berlin, New York: Mouton de Gruyter, 1-47.

Aijmer, Karin and Anne-Marie Simon-Vandenbergen (2009) "Pragmatic Markers". In: Östman, Jan-Ola and Jef Verschueren (eds.) Handbook of Pragmatics. Amsterdam: John Benjamins.

Bakhtin, Mikhail (1987) The Dialogic Imagination: 4 Essays. Austin: University of Texas Press.

Blakemore, Diane (1992) Understanding Utterances. An Introduction to Pragmatics. Oxford: Blackwell.

Chafe, Wallace (1986) "Evidentiality in English conversation and academic writing”. In: Chafe, Wallace and Johanna Nichols (eds.) Evidentiality: The Linguistic Coding of Epistemology. Norwood, NJ: Ablex, 261-272.

Chafe, Wallace. (1994) Discourse, Consciousness, and Time: The Flow and Displacement of Conscious Experience in Speaking and Writing. Chicago: University of Chicago Press.

Crystal, David and Derek Davy (1975) Advanced Conversational English. London: Longman.

Csüry, István (2011) "A forgatókönyv mint elméleti kategória és kommunikációs eseménytípus multimodális megközelítésben”. In: Németh T. Enikő (ed.): Ember-gép kapcsolat. A multimodális ember-gép kommunikáció modellezésének alapjai. Segédkönyvek a nyelvészet tanulmányozásához 133. Budapest: Tinta Könyvkiadó, 145-178

Fetzer, Anita (2000) "Negotiating validity claims in political interviews". Text 20 (4), 1-46. 
Fetzer, Anita (2008) "Theme zones in contrast: An analysis of their linguistic realization in the communicative act of non-acceptance". In: Gómez-González, Maria de los Ángeles, J. Lachlan Mackenzie and Elsa M. González Álvarez (eds.) Languages and Cultures in Contrast and Comparison. Amsterdam: John Benjamins, 3-32.

Fetzer, Anita and Elda Weizman (2006) "Political Discourse as Mediated and Public Discourse". Journal of Pragmatics 38, 143-153.

Fraser, Bruce (1996) "Pragmatic markers". Pragmatics 6, 167-190.

Fraser, Bruce (1999) "What are discourse markers?" Journal of Pragmatics 31, 931-952.

Fraser, Bruce (2009) “Topic orientation markers". Journal of Pragmatics 41, 892-898.

Furkó, Bálint Péter (2007) "The status of of course as a discourse marker". In: Balogné Bérces, K., Földváry, Kinga and Rita Mészárosné Kóris (eds.) Proceedings of the HUSSE10 Conference. HUSSE10-Linx. Debrecen: Hungarian Society for the Study of English, 95-106. http:// husse-esse.hu/wp-content/2007/04/furko-peter-of-course-as-a-dm.doc (accessed on 27 September 2011)

Goffman, Erving (1981) Forms of Talk. Philadelphia: University of Pennsylvania

González, Montserrat (2004) Pragmatic Markers in Oral Narrative - the Case of English and Catalan. Amsterdam and Philadelphia: John Benjamins.

Halliday, Michael A. K. and Ruqaya Hasan (1976) Cohesion in English. London: Longman.

Heritage, John (2002) "Oh-prefaced responses to assessments: a method of modifying agreement/ disagreement". In: Ford, Cecilia, Barbara Fox and Sandra Thompson (eds.) The Language of Turn and Sequence. New York: Oxford University Press, 196-224.

Heritage, John and David L. Greatbatch (1991) "On the institutional character of institutional talk: the case of news interviews". In: Deirdre, Boden and Donald H. Zimmerman (eds.) Talk and Social Structure: Studies in Ethnomethodology and Conversation Analysis. Berkley: University of California Press, 93-137.

Holmes, Janet (1988) “Of course: a pragmatic particle in New Zealand women's and men's speech". Australian Journal of Linguistics 2, 49-74.

Holmes, Janet (1990) "Hedges and boosters in women's and men's speech". Language and Communication 10, 185-205.

Jucker, Andreas H. and Sara W. Smith (1998) “And people just you know like 'wow': Discourse markers as negotiating strategies”. In: Jucker, Andreas H. and Yael Ziv (eds.) Discourse Markers: Descriptions and Theory. Amsterdam and Philadelphia: John Benjamins, 171-203.

Lauerbach, Gerda (2006) "Discourse representation in political interviews: The construction of identities and relations through voicing and ventriloquizing". Journal of Pragmatics 38, 196-215.

Lauerbach, Gerda (2007) “Argumentation in Political Talk Show Interviews”. Journal of Pragmatics 39, 1388-1419.

Lenk, Uta (1998) "Discourse markers and global coherence in conversation". Journal of Pragmatics 30, 245-257.

Lewis, Diane (2006) "Discourse markers in English: a discourse-pragmatic view". In: Fischer, Kerstin (ed.) Approaches to Discourse Particles. Amsterdam: Elsevier, 43-59.

O'Barr, William and Bowman Atkins (1980) “'Women's language' or 'powerless language"”. In: McConnell-Ginet, Sally, Ruth Borker and Nelly Furman (eds.) Women and Language in Literature and Society. New York: Praeger, 93-110.

Östman, Jan-Ola (1995) "Pragmatic particles twenty years after". In Wårvik, Brita, Sanna-Kaisa Tanskanen and Risto Hiltunen (eds.) Organization in discourse. Proceedings from the Turku Conference. Turku: University of Turku, 95-108.

Petukhova, Volha and Harry C. Bunt (2009) "Towards a multidimensional semantics of discourse markers in spoken dialogue". Proceedings of the $8^{\text {th }}$ International Conference on Computational Semantics. Tilburg, 157-168.

Redeker, Gisela (1991) "Linguistic markers of discourse structure". Linguistics 29, 1139-1172.

Redeker, Gisela (2006) "Discourse markers as attentional cues at discourse transitions". In: Fischer, Kerstin (ed.) Approaches to discourse particles. Oxford: Elsevier, 339-358. 
Sacks, Harvey (1992) Lectures on Conversation. Oxford: Blackwell.

Saz Rubio, Maria Milagros del (2007) English Discourse Markers of Reformulation. Bern: Peter Lang.

Schegloff, Emanuel (1972) "Notes on a Conversational Practice: Formulating Place". In: Sudnow, David N. (ed.) Studies in Social Interaction. New York: Free Press, 75-119.

Schiffrin, Deborah (1987) Discourse Markers. Cambridge: Cambridge University Press.

Schourup, Lawrence (1985) Common Discourse Particles in English Conversation. New York: Garland.

Simon-Vandenbergen, Anne-Marie (1988) "What really really means in casual conversation and in political interviews". Linguistica Antverpiensia 22, 206-225.

Simon-Vandenbergen, Anne-Marie (1992) "The interactional utility of of course in spoken discourse". Occasional Papers in Systemic Linguistics 6, 213-226.

Simon-Vandenbergen, Anne-Marie and Karin Aijmer (2002/03) "The expectation marker 'of course". Languages in Contrast 4, 13-43.

Simon-Vandenbergen, Anne-Marie, Peter R.R. White and Karin Aijmer (2007) "Presupposition and 'taking-for-granted' in mass communicated political argument: An illustration from British, Flemish and Swedish political colloquy". In: Fetzer, Anita and Gerda E. Lauerbach (eds.) Political Discourse in the Media. Amsterdam and Philadelphia: John Benjamins, 31-75.

Sperber, Dan and Wilson, Deirdre (1986/1995) Relevance: Communication and Cognition. $2^{\text {nd }}$ edition. Oxford: Blackwell.

Stenström, Anna-Brita (1990) "Lexical items peculiar to spoken discourse". In: Svartvik, Jan (ed.) The London-Lund Corpus of Spoken English: Description and Research. Lund: Lund University Press, 137-175.

Stenström, Anna-Brita (1994) An Introduction to Spoken Interaction. London and New York: Longman.

Swan, Michael (1997) Practical English Usage. Oxford: Oxford University Press.

Tannen, Deborah (2010) "Abduction in family interaction: Ventriloquizing as indirectness". Journal of Pragmatics 42, 307-316.

White, Peter (2000) "Dialogue and inter-subjectivity: reinterpreting the semantics of modality and hedging". In: Coulthard, Malcolm, Janet Cotterill and Francis Rock (eds.) Dialogue Analysis VII: Working with Dialogue. Selected Papers from the $7^{\text {th }}$ International Association of Dialogue Analysis Conference. Tübingen: Niemeyer, 67-80.

Wichmann, Anne, Anne-Marie Simon-Vandenbergen and Karin Aijmer (2010) "How prosody reflects semantic change: A synchronic case study of of course”. In: Davidse, Kristin, Lieven Vandelanotte and Hubert Cuyckens (eds.) Subjectification, Intersubjectification and Grammaticalization. Berlin and NY: De Gruyter Mouton, 103-155.

Zovko, Ivana (2012) "Analysis of discourse markers in the Interviews with presidents of Bosnia and Herzegovina and the U.S.A.". In: 2nd International Conference on Foreign Language Teaching and Applied Linguistics (FLTAL'12). Sarajevo.

PÉTER FuRKó, PhD, is an associate professor at the Department of English Linguistics, Károli Gáspár University of the Reformed Church in Hungary. His research interests include the sociolinguistics/ pragmatics interface, the pragmatic marker/discourse marker dichotomy, cross-cultural pragmatics, and the study of media discourse. His papers have appeared in a number of British, Hungarian, Romanian, Slovakian and Ukrainian publications. He has published the book The pragmatic marker - discourse marker dichotomy reconsidered: The case of 'well' and 'of course' (2007, Debrecen: Debrecen University Press).

Address: Dr. Péter Bálint Furkó, Institute of English Studies, Károli Gáspár University of the Reformed Church in Hungary, H-1088 Budapest, Reviczky utca 4, Hungary. [email: furko.peter@ gmail.com] 
ÁGNES ABUCZKI is an assistant researcher at the MTA-DE (Hungarian Academy of Sciences - University of Debrecen) Research Group for Theoretical Linguistics. Her academic interests include Conversation Analysis, Computational Pragmatics and Relevance Theory. She has published in several international journals and conference proceedings, such as the Springer Journal on Multimodal User Interfaces, the IEEE International Journal on Cognitive Infocommunications and the LNCS Cognitive Behavioural Systems. She is currently working on her PhD dissertation entitled A Core/Periphery Approach to the Functional Spectrum of Discourse Markers in Multimodal Context.

Address: Ágnes Abuczki, MTA-DE Research Group for Theoretical Linguistics, Hungary, H-4010 Debrecen Pf. 47, Hungary. [email: abuczki.agnes@gmail.com] 